\title{
Discharge diagnoses versus medical record review in the identification of community- acquired sepsis
}

Henry E Wang ${ }^{1 *}$, Dylan R Addis ${ }^{2}$, John P Donnelly ${ }^{1,3,4}$, Nathan I Shapiro ${ }^{5}$, Russell L Griffin ${ }^{3}$, Monika M Safford ${ }^{4}$ and John W Baddley ${ }^{6}$

\begin{abstract}
Introduction: We evaluated the accuracy of hospital discharge diagnoses in the identification of communityacquired sepsis and severe sepsis.

Methods: We reviewed 379 serious infection hospitalizations from 2003 to 2012 from the national populationbased reasons for geographic and racial differences in stroke (REGARDS) cohort. Through manual review of medical records, we defined criterion-standard community-acquired sepsis events as the presence of a serious infection on hospital presentation with $\geq 2$ systemic inflammatory response syndrome criteria. We also defined criterion-standard community-acquired severe sepsis events as sepsis with $>1$ sequential organ failure assessment organ dysfunction. For the same hospitalizations, we identified sepsis and severe sepsis events indicated by Martin et al. and Angus et al. International Classifications of Diseases 9th edition discharge diagnoses. We evaluated the diagnostic accuracy of the Martin and Angus criteria for detecting criterion-standard community-acquired sepsis and severe sepsis events.

Results: Among the 379 hospitalizations, there were 156 community-acquired sepsis and 122 community-acquired severe sepsis events. Discharge diagnoses identified 55 Martin-sepsis and 89 Angus-severe sepsis events. The accuracy of Martin-sepsis criteria for detecting community-acquired sepsis were: sensitivity 27.6\%; specificity 94.6\%; positive predictive value (PPV) 78.2\%; negative predictive value (NPV) 65.1\%. The accuracy of the Angus-severe sepsis criteria for detecting community-acquired severe sepsis were: sensitivity 42.6\%; specificity 86.0\%; PPV 58.4\%; NPV 75.9\%. Mortality was higher for Martin-sepsis than community-acquired sepsis ( $25.5 \%$ versus $10.3 \%, P=0.006$ ), as well as for Angus-severe sepsis than community-acquired severe sepsis (25.5 versus $11.5 \%, P=0.002)$. Other baseline characteristics were similar between sepsis groups.

Conclusions: Hospital discharge diagnoses show good specificity but poor sensitivity for detecting communityacquired sepsis and severe sepsis. While sharing similar baseline subject characteristics as cases identified by hospital record review, discharge diagnoses selected for higher mortality sepsis and severe sepsis cohorts. The epidemiology of a sepsis population may vary with the methods used for sepsis event identification.
\end{abstract}

\section{Introduction}

Sepsis is a major public health problem. Prior studies estimate that severe sepsis is responsible for over 750,000 hospital admissions, 570,000 emergency department visits, 200,000 hospital deaths and $\$ 16$ billion in hospital expenditures in the United States annually $[1,2]$.

\footnotetext{
* Correspondence: hwang@uabmc.edu

'Department of Emergency Medicine, University of Alabama School of Medicine, 619 19th Street South, OHB 251, Birmingham, AL 35249, USA Full list of author information is available at the end of the article
}

An important step in reducing the national impact of sepsis is to quantify and characterize the affected patient population. Prior epidemiologic studies have applied a range of strategies to identify sepsis and severe sepsis using hospital diagnoses [1-8]. For example, Martin and colleagues identified sepsis hospitalizations using the International Classifications of Diseases, 9th edition (ICD-9) discharge diagnoses specific for sepsis or septicemia [3]. Angus and colleagues identified severe sepsis

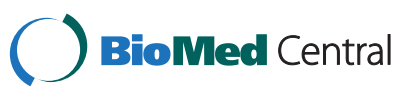

(c) 2015 Wang et al.; licensee BioMed Central. This is an Open Access article distributed under the terms of the Creative Commons Attribution License (http://creativecommons.org/licenses/by/4.0), which permits unrestricted use, distribution, and reproduction in any medium, provided the original work is properly credited. The Creative Commons Public Domain Dedication waiver (http://creativecommons.org/publicdomain/zero/1.0/) applies to the data made available in this article unless otherwise stated. 
cases as hospitalizations with discharge diagnoses for both a serious infection and organ dysfunction [1].

While the analysis of administrative datasets leverages the efficiency of large pre-existing data, these approaches are limited by variations in physician documentation and hospital coding practices, and by the absence of physiologic or laboratory values [9]. Most importantly, discharge diagnoses are unable to distinguish initial communityacquired sepsis from later hospital-acquired sepsis. This distinction is important because sepsis detection and treatment strategies and the characteristics of affected patients probably differ between the two settings. Sepsis care guidelines generally focus on the early detection and treatment of community-acquired sepsis in the emergency department [10].

A more definitive strategy for identifying communityacquired sepsis is through the structured manual review of medical records, integrating information from physician and nursing notes, physiologic measurements and laboratory values during the patient's initial hospital presentation. In this study we sought to determine the accuracy of discharge diagnoses for detecting communityacquired sepsis and severe sepsis among individuals hospitalized with a serious infection. We also sought to compare and contrast the characteristics of sepsis and severe sepsis cohorts identified by these methods.

\section{Materials and methods Study design}

This study utilized data from the Reasons for Geographic and Racial Differences in Stroke (REGARDS) study, a national, population-based, longitudinal cohort, and REGARDS-Sepsis, an ancillary study identifying community-acquired sepsis events in the REGARDS cohort. The Institutional Review Board of the University of Alabama at Birmingham approved the study. Individuals provided written consent for participation in the REGARDS study.

\section{The REGARDS cohort}

Designed to evaluate reasons for geographic and racial variations in stroke mortality, the REGARDS cohort is one of the largest ongoing national cohorts of communitydwelling individuals in the United Sates [11]. The cohort encompasses 30,239 individuals $\geq 45$ years old, with $42 \%$ African American and 45\% male. Approximately 69\% of individuals are $>60$ years old. The REGARDS cohort includes individuals from all regions of the continental United States, with $21 \%$ of the cohort originating from the coastal plains of North Carolina, South Carolina and Georgia (the buckle of the stroke belt) and 35\% originating from the remainder of North Carolina, South Carolina and Georgia plus Tennessee, Mississippi, Alabama, Louisiana and Arkansas (the stroke belt). The REGARDS cohort does not include Hispanics, where stroke mortality disparities are small to nonexistent.

The REGARDS study enrolled participants during 2003 to 2007. The REGARDS study determined baseline data for each participant through telephone interviews and in-person evaluations. Baseline information included medical history, functional status, health behaviors, physical characteristics (height, weight), physiologic measures (blood pressure, pulse, electrocardiogram) and an inventory of medications. The study obtained blood and urine specimens from each participant. Participants also completed self-administered questionnaires regarding diet, family history of diseases, psychosocial factors and prior residences.

As is customary for studies of this design, the REGARDS study contacts each participant on a semiannual basis to determine the date, location and attributed reason for all emergency department visits and hospitalizations during the follow-up interval. For each participant death, the study reviews related death and medical records and interviews proxies to ascertain the circumstances of the death event.

\section{Selection of participants - identification of serious infection hospitalization events}

We reviewed medical records for hospitalizations attributed by participants to a serious infection. We defined a serious infection using the taxonomy of Angus and colleagues [1] Two trained abstractors independently reviewed all pertinent medical records to confirm, first, the presence of a serious infection on initial hospital presentation and, second, its role as a major reason for hospitalization. The medical record review included physician and nursing clinical notes as well as laboratory records. Because some patients may not manifest sepsis signs until after initial emergency department presentation, we used the worst vital signs and laboratory values from first 28 hours of hospitalization, a period designed to encompass the emergency department and up to 1 day of inpatient care. The abstractors adjudicated discordances, with additional physician-level review as needed. Initial review indicated excellent inter-rater agreement for the presence of a serious infection $(\kappa=0.92)$. We examined hospitalization events occurring during 2003 to 2012.

The larger REGARDS-Sepsis study encompassed 3,431 serious infection hospitalizations observed among cohort participants. The current analysis focused on a subset of 379 serious infection events with ICD-9 discharge diagnoses available for review. This subset was identified during the early pilot stages of the larger REGARDS-Sepsis study.

\section{Identification of criterion-standard community-acquired sepsis and severe sepsis events}

Among the serious infection events, we reviewed available hospital records to determine the criterion-standard 
presence of community-acquired sepsis and severe sepsis. We defined criterion-standard community-acquired sepsis as presentation to the hospital with an infection plus two or more systemic inflammatory response syndrome criteria, including: heart rate $>90$ beats/minute; fever (temperature $>38.3^{\circ} \mathrm{C}$ or $<36^{\circ} \mathrm{C}$ ); tachypnea $(>20$ breaths/minute) or $\mathrm{PCO}_{2}<32 \mathrm{mmHg}$; and leukocytosis (white blood cells $>12,000$ or $<4,000$ cells $/ \mathrm{mm}^{3}$ or $>10 \%$ band forms). Because of our focus on communityacquired sepsis, we used the most abnormal vital signs and laboratory test results for the initial 28 hours of hospitalization. We defined criterion-standard communityacquired severe sepsis as the presence of sepsis with concurrent organ dysfunction. We determined organ dysfunctions using Sequential Organ Failure Assessment (SOFA) based upon the most abnormal laboratory and physiologic findings during the first 28 hours of hospitalization for respiratory, renal, hepatic, cardiovascular, hematologic, and neurologic systems [12]. Missing values were coded as zero or absent in the determination of systemic inflammatory response syndrome and SOFA elements.

\section{Identification of sepsis and severe sepsis using discharge diagnoses}

For the discharge diagnosis-based identification of sepsis, we used the ICD-9 codes of Martin and colleagues (Martin-sepsis) [3] (Additional file 1). We expanded the Martin-sepsis codes to include ICD-9 codes 785.52 (septic shock), 995.91 (sepsis) and 995.92 (severe sepsis) [3]. For the discharge diagnosis-based identification of severe sepsis, we used the ICD-9 codes of Angus and colleagues (Angus-severe sepsis), defining severe sepsis as the presence of discharge diagnoses for both an infection and organ dysfunction [1] (Additional file 2). As with prior studies, we expanded the Angus-severe sepsis criteria to include mechanical ventilation (ICD-9p 96.7) as a form of respiratory organ dysfunction [2]. If the diagnosis 785.52 (septic shock) or the diagnosis 995.92 (severe sepsis) was present, we classified the event as Angus-severe sepsis.

\section{Participant characteristics, hospital course and outcomes}

The REGARDS participant sociodemographic data used in this analysis included age, sex, race, annual household income and education (years of school). The REGARDSdefined alcohol use categories included none, moderate (one drink per day for women or two drinks per day for men) and heavy ( $>1$ drink per day for women and $>2$ drinks per day for men) [13]. Tobacco use categories included none, current and prior smoking.

Participant chronic medical conditions included atrial fibrillation, cancer history, chronic lung disease, chronic kidney disease, coronary artery disease, deep vein thrombosis, diabetes, dyslipidemia, hypertension, myocardial infarction, obesity, peripheral artery disease and stroke. Atrial fibrillation was identified by participant self-report or baseline electrocardiogram. Chronic kidney disease was defined as an estimated glomerular filtration rate $<60 \mathrm{ml} /$ minute $/ 1.73 \mathrm{~m}^{2}$ based upon the CKD-EPI equation [14]. Coronary artery disease included a history of myocardial infarction or coronary intervention. Diabetes was defined as fasting glucose $\geq 126 \mathrm{mg} / \mathrm{l}$ (or glucose $\geq 200 \mathrm{mg} / \mathrm{l}$ for those not fasting) or the use of insulin or oral hypoglycemic agents. Dyslipidemia consisted of individuals with self-reported high cholesterol or the use of lipid-lowering medications. Hypertension included systolic blood pressure $\geq 140 \mathrm{mmHg}$, diastolic blood pressure $\geq 90 \mathrm{mmHg}$, or the self-reported use of antihypertensive agents. Myocardial infarction included those with a self-reported history of myocardial infarction or baseline electrocardiographic evidence of myocardial infarction.

Obesity was defined as a waist circumference $>102 \mathrm{~cm}$ for males or $>88 \mathrm{~cm}$ for females, or body mass index $\geq 30$ $\mathrm{mg} / \mathrm{cm}^{2}$ [15]. Participants self-reported the prior history of stroke (including transient ischemic attacks) or deep vein thrombosis. Peripheral artery disease included a history of lower extremity arterial bypass or leg amputation. The REGARDS study did not collect information on pulmonary conditions such as asthma and chronic obstructive pulmonary disease, and thus we defined chronic lung disease as participant use of pulmonary medications such as beta agonists, leukotriene inhibitors, inhaled corticosteroids, combination inhalers, ipatropium, cromolyn, aminophylline and theophylline.

Examined hospital course characteristics included the SOFA score for the first 28 hours of hospitalization, the Mortality in Emergency Department Sepsis (MEDS) score, admission to the ICU and hospital death $[12,16,17]$.

\section{Statistical analysis}

We assessed the accuracy of the Martin-sepsis criteria for detecting community-acquired sepsis events. We similarly determined the accuracy of the Angus-severe sepsis criteria for detecting community-acquired severe sepsis events. Examined diagnostic parameters included sensitivity, specificity, positive predictive value, negative predictive value, positive and negative likelihood ratio tests, and area under the receiver-operating characteristics curve.

To contrast participant characteristics and hospital course of Martin-sepsis with community-acquired subgroups, we followed the methodology of Muntner and colleagues, comparing the prevalence of each variable in events with discordant sepsis classifications (that is, Martin-sepsis[+]/community-acquired sepsis[-] or Martinsepsis[-]/community-acquired sepsis[+]) [18]. We conducted the latter comparisons using univariable logistic regression, fitting a series of models with the discordance 
Table 1 Detection of community-acquired sepsis by Martin and colleagues' discharge diagnoses [3]

\begin{tabular}{|c|c|c|c|}
\hline \multirow[b]{2}{*}{ Sepsis identified by Martin and colleagues' discharge diagnosis codes } & \multicolumn{2}{|c|}{ Community-acquired sepsis } & \multirow[b]{2}{*}{ Total } \\
\hline & Sepsis & No sepsis & \\
\hline Sepsis & 43 & 12 & 55 \\
\hline No sepsis & 113 & 211 & 324 \\
\hline Total & 156 & 214 & 379 \\
\hline
\end{tabular}

Total of 379 serious infection hospitalizations.

pattern as the dependent variable and each participant or hospital course characteristic as an independent variable. We made similar comparisons between Angus-severe sepsis and community-acquired severe sepsis cases. We conducted all statistical analyses using Stata version 12.1 (Stata, Inc., College Station, TX, USA).

\section{Results}

The study included 379 hospitalizations with available discharge diagnoses. Among these cases, there were 156 (41.2\%) criterion-standard community-acquired sepsis events (Table 1). Discharge diagnoses indicated 55 (14.5\%) cases meeting Martin-sepsis criteria. The Martin-sepsis criteria detected 43 (27.6\%) of 156 community-acquired sepsis cases (Table 2). There were 125 (33.0\%) discordances between community-acquired sepsis and Martinsepsis classifications.

While the sensitivity of the Martin-sepsis criteria for community-acquired sepsis events was low (27.6\%), specificity was high (94.6\%) (Table 2). Of the 113 community-acquired sepsis cases missed by the Martinsepsis criteria, the infection types were as follows: lung ( $n$ $=65,57.5 \%)$, kidney $(n=15,13.3 \%)$, abdominal $(n=22$, $19.5 \%)$, skin $(n=6,5.3 \%)$ and other $(n=5,4.4 \%)$. When stratified by infection type, sensitivity of the Martin-sepsis criteria was slightly higher for other infections (68.8\%). Specificity was very high for lung (98.8\%) and abdominal (98.0\%) infections.

Compared with community-acquired sepsis, Martinsepsis individuals were more likely to have atrial fibrillation and diabetes. (Table 3). Sociodemographics, health behaviors, other chronic medical conditions, initial SOFA and MEDS scores, and ICU admission rates were similar between community-acquired sepsis and Martin-sepsis cases. Hospital mortality was higher for Martin-sepsis than for community-acquired sepsis (25.5 vs. $10.3 \%, P=0.006)$.

Among the 379 serious infection hospitalizations, there were $122(32.2 \%)$ criterion-standard communityacquired severe sepsis events (Table 4). Discharge diagnoses indicated 89 (23.5\%) cases meeting Angus-severe sepsis criteria. The Angus-severe sepsis criteria detected 52 (42.6\%) of 122 community-acquired severe sepsis cases. While sensitivity of the Angus-severe sepsis criteria for community-acquired severe sepsis events was low (42.6\%), specificity was higher (86.0\%) (Table 5). Of the 70 community-acquired severe sepsis events missed by the Angus-severe sepsis criteria, the infection types were as follows: lung $(n=36,51.4 \%)$, kidney $(n=13,18.6 \%)$, abdominal $(n=12,17.1 \%)$, skin $(n=4,5.7 \%)$ and other $(n=5,7.1 \%)$. When stratified by infection type, the sensitivity of Angus-severe sepsis criteria was slightly higher for other infections (58.3\%), and specificity was slightly higher for skin (90.5\%) and other infections (90.0\%).

Compared with community-acquired severe sepsis, Angus-severe sepsis individuals were older and exhibited higher initial SOFA scores (Table 6). Other sociodemographics, health behaviors, chronic medical conditions, MEDS scores, and ICU admission rates were similar between community-acquired severe sepsis and Angus-severe sepsis cases. Hospital mortality was higher for Angus-severe sepsis than for community-acquired severe sepsis $(22.5 \%$ vs. $11.5 \%, P=0.002)$.

Table 2 Classification accuracy of Martin and colleagues' criteria in detecting community-acquired sepsis events, stratified by infection category [3]

\begin{tabular}{|c|c|c|c|c|c|c|}
\hline Diagnostic $p$ & Lung $(n=166)$ & Kidney $(n=59)$ & Abdominal $(n=73)$ & Skin $(n=49)$ & Other $(n=32)$ & Overall $(n=379)$ \\
\hline ensitivity (\%) & 18.8 (10.9 to 29.0$)$ & 44.4 (25.5 to 64.7$)$ & $4.4(0.11$ to 21.9$)$ & 40.0 (12.2 to 73.8$)$ & 68.8 (41.3 to 89.0$)$ & $27.6(20.7$ \\
\hline & 8.8 (93.7 to 100.0 ) & 90.6 (75.0 to 98.0$)$ & $98.0(89.4 \mathrm{t}$ & 94.9 (82.7 to 99.4$)$ & $68.8(41.3$ & 94.6 \\
\hline ssitive prec & 93.8 (69.8 to 99.8 ) & 80.0 (51.9 to 95.7$)$ & 50.0 & 95.7) & 68.8 & $78.2(65$. \\
\hline lue (\%) & 56.7 (48.3 to 64.7$)$ & $65.9(50.1$ to 79.5$)$ & 69.0 (56.9 to 79.5$)$ & $86.0(72$. & 68.8( & $65.1(59$. \\
\hline Likelihood ratio positive & 16.1 (2.2 to 119.0$)$ & 4.7 (1.5 to 15.1$)$ & & 7.8 (1.7 to 36.7 ) & 2.2 (0.99 to 9.9 ) & 5.1 (2.8 to 9.4 ) \\
\hline Likelihood ratio & 0.82 (0.74 to 0.92 ) & 0.61 (0.43 to 0.88 ) & 0.98 (0.89 to 1.07 ) & 0.63 (0.38 to 1.05 ) & 0.46 (0.21 to 1.01$)$ & 0.77 (0.69 to 0.8 \\
\hline Area under ROC curve & 0.59 (0.54 to 0.63 ) & 0.68 (0.57 to 0.78$)$ & 0.51 (0.47 to 0.56$)$ & 0.67 (0.51 to 0.84$)$ & 0.69 (0.41 to 0.89 ) & 0.61 (0.57 to 0.65 \\
\hline
\end{tabular}

Data presented as mean (95\% confidence interval). ROC, receiver operating characteristics. 
Table 3 Baseline characteristics and hospital course of community-acquired sepsis events (identified by manual chart review) and sepsis events identified by Martin and colleagues' discharge diagnoses

\begin{tabular}{|c|c|c|c|c|c|}
\hline Characteristic & $\begin{array}{l}\text { Community-acquired } \\
\text { sepsis (column \%) } \\
(n=156)\end{array}$ & $\begin{array}{l}\text { Martin-sepsis } \\
\text { (column\%) } \\
(n=55)\end{array}$ & $\begin{array}{l}\text { Discordances favoring } \\
\text { community-acquired } \\
\text { sepsis (column \%) } \\
(n=113)\end{array}$ & $\begin{array}{l}\text { Discordances favoring } \\
\text { Martin-sepsis (column \%) } \\
(n=12)\end{array}$ & $\begin{array}{l}P \text { value Community- } \\
\text { acquired versus } \\
\text { Martin-sepsis } \\
\text { discordances }^{\mathrm{a}}\end{array}$ \\
\hline Mean age (SD) & $69.7(9.1)$ & $70.6(8.8)$ & $69.3(9.3)$ & $70.3(10.3)$ & 0.72 \\
\hline \multicolumn{6}{|l|}{ Sex } \\
\hline Male & 58.3 & 67.3 & 54.9 & 66.7 & \multirow[t]{2}{*}{0.43} \\
\hline Female & 41.7 & 32.7 & 45.1 & 33.3 & \\
\hline \multicolumn{6}{|l|}{ Race } \\
\hline White & 64.7 & 58.2 & 68.1 & 33.3 & \multirow[t]{2}{*}{0.92} \\
\hline Black & 35.3 & 41.8 & 31.9 & 66.7 & \\
\hline \multicolumn{6}{|l|}{ Income } \\
\hline$<\$ 20,000$ & 25.6 & 27.3 & 25.7 & 33.3 & \multirow[t]{5}{*}{0.70} \\
\hline$\$ 20,000$ to 34,000 & 37.2 & 41.8 & 34.5 & 33.3 & \\
\hline$\$ 35,000$ to 74,000 & 21.8 & 21.8 & 21.2 & 16.7 & \\
\hline$\geq \$ 75,000$ & 9.6 & 1.8 & 12.4 & 0.0 & \\
\hline Unknown & 5.8 & 7.3 & 6.2 & 16.7 & \\
\hline \multicolumn{6}{|l|}{ Education } \\
\hline Less than high school & 22.4 & 21.8 & 21.2 & 8.3 & \multirow[t]{4}{*}{0.70} \\
\hline High school graduate & 31.4 & 30.9 & 32.7 & 41.7 & \\
\hline Some college & 28.2 & 27.3 & 29.2 & 33.3 & \\
\hline College or higher & 18.0 & 20.0 & 16.7 & 16.7 & \\
\hline \multicolumn{6}{|l|}{ Health behaviors } \\
\hline \multicolumn{6}{|l|}{ Tobacco use } \\
\hline Never & 32.3 & 34.6 & 32.1 & 41.7 & \multirow[t]{3}{*}{0.79} \\
\hline Past & 52.3 & 52.7 & 50.9 & 41.7 & \\
\hline Current & 15.5 & 12.7 & 17.0 & 16.7 & \\
\hline \multicolumn{6}{|l|}{ Alcohol use } \\
\hline None & 67.7 & 67.3 & 69.6 & 83.3 & \multirow[t]{3}{*}{0.36} \\
\hline Moderate & 29.0 & 29.1 & 27.7 & 16.7 & \\
\hline Heavy & 3.2 & 3.6 & 2.7 & 0.0 & \\
\hline \multicolumn{6}{|l|}{ Chronic medical conditions } \\
\hline Atrial fibrillation & 15.6 & 17.3 & 17.8 & 50.0 & 0.03 \\
\hline Cancer & 19.5 & 22.2 & 19.0 & 27.3 & 0.53 \\
\hline Chronic kidney disease & 26.9 & 27.3 & 25.7 & 16.7 & 0.48 \\
\hline Chronic lung disease & 18.0 & 7.3 & 22.1 & 8.3 & 0.22 \\
\hline Coronary artery disease & 29.6 & 24.5 & 33.3 & 41.7 & 0.57 \\
\hline Deep vein thrombosis & 12.9 & 16.4 & 11.6 & 16.7 & 0.62 \\
\hline Diabetes & 35.3 & 47.3 & 34.5 & 83.3 & $<0.001$ \\
\hline Dyslipidemia & 66.7 & 70.0 & 64.2 & 55.6 & 0.61 \\
\hline Hypertension & 70.3 & 35.5 & 71.4 & 58.3 & 0.36 \\
\hline Myocardial infarction & 18.3 & 20.8 & 18.8 & 33.3 & 0.26 \\
\hline Obesity (abnormal BMl or WC) & 62.8 & 63.6 & 61.1 & 50.0 & 0.46 \\
\hline Peripheral artery disease & 3.9 & 5.5 & 3.54 & 8.33 & 0.47 \\
\hline Stroke & 19.4 & 25.5 & 18.8 & 41.7 & 0.09 \\
\hline
\end{tabular}


Table 3 Baseline characteristics and hospital course of community-acquired sepsis events (identified by manual chart review) and sepsis events identified by Martin and colleagues' discharge diagnoses (Continued)

\begin{tabular}{|c|c|c|c|c|c|}
\hline \multicolumn{6}{|l|}{ Infection type } \\
\hline Lung & 51.3 & 29.1 & 57.5 & 8.3 & $<0.001$ \\
\hline Kidney & 17.3 & 27.3 & 13.3 & 25.0 & \\
\hline Abdominal & 14.7 & 3.6 & 19.5 & 8.3 & \\
\hline Skin & 6.4 & 10.9 & 5.3 & 16.7 & \\
\hline Other & 10.3 & 29.1 & 4.4 & 41.7 & \\
\hline 28-hour SOFA score & $2(1$ to 3$)$ & $2(1$ to 3$)$ & $1(0$ to 3$)$ & $2(1$ to 3$)$ & 0.56 \\
\hline Median (IQR) MEDS score & 9 (6 to 13$)$ & $11(6$ to 13$)$ & $9(6$ to 11$)$ & $9(6$ to 10.5$)$ & 0.12 \\
\hline Admission to ICU & 13.5 & 23.6 & 8.0 & 8.3 & 0.96 \\
\hline Hospital mortality & 10.3 & 25.5 & 5.3 & 33.3 & 0.006 \\
\hline
\end{tabular}

BMI, body mass index; IQR, interquartile range; MEDS, Mortality in Emergency Department Sepsis; SD, standard deviation; SOFA, Sequential Organ Failure Assessment; WC, waist circumference. ${ }^{\text {a }}$ The prevalence of each subject characteristic was evaluated by comparing the discordant pairs for each sepsis definition.

\section{Discussion}

Prior studies have used hospital discharge diagnoses to characterize the epidemiology of sepsis and severe sepsis [1-7]. Using hospital event data from a national population-based cohort, our study offers unique perspectives of this strategy for sepsis identification. Our study confirms that the Martin-sepsis and Angus-severe sepsis diagnoses are specific but poorly sensitive for identifying community-acquired sepsis and severe sepsis determined through structured review of initial hospital data. Our study also confirmed that the Martin-sepsis and Angus-severe sepsis criteria select for populations with higher hospital mortality rates.

The findings of this study neither support nor refute the merits of any particular sepsis identification strategy. Rather, our analysis highlights the distinct features and trade-offs of each approach (Table 7). Advantages of medical record review include the use of physiologic measurements and laboratory test values, and better affirmation of a potential linkage with an underlying infection. However, manual chart review is clearly more arduous. While efficiently utilizing existing hospital data, discharge diagnoses may miss sepsis or severe sepsis cases not recognized or documented by clinicians, or not coded by billing personnel. The community-acquired sepsis and severe sepsis cases missed by the Martin-sepsis and Angus-severe sepsis criteria were predominantly due to lung infections, suggesting that gaps in sepsis coding and documentation practices may be most pronounced in this subset.

The Martin-sepsis and Angus-severe sepsis criteria are believed to be poorly sensitive but highly specific for identifying sepsis and severe sepsis hospitalizations. One would expect Martin and colleagues' and Angus and colleagues' criteria to exhibit increased sensitivity and decreased specificity when limited to community-acquired sepsis and severe sepsis detection. However, we observed that the low sensitivity and high specificity of these criteria persisted even when limited in this manner. This finding has two important implications. First, the low sensitivity may reflect inherent underdetection of all sepsis and severe sepsis events, not the relative proportions of community-acquired versus hospital-acquired sepsis cases. Secondly, the high specificity suggests that, when present, sepsis and severe sepsis-related discharge diagnoses may tend to be associated with communityacquired cases.

The varying approaches to sepsis identification may result in study populations with markedly different patient characteristics. Using hospital discharge data for

Table 4 Detection of community-acquired severe sepsis by Angus and colleagues' discharge diagnoses

\begin{tabular}{llll} 
& \multicolumn{3}{c}{ Community-acquired severe sepsis } \\
\cline { 2 - 3 } Severe sepsis identified by Angus and colleagues' discharge diagnoses & Severe sepsis & No severe sepsis & 37 \\
\hline Severe sepsis & 52 & 220 & Total \\
No severe sepsis & 70 & 257 & 290 \\
Total & 122 & 379 \\
\hline
\end{tabular}

Total of 379 serious infection hospitalizations. 
Table 5 Diagnostic accuracy of Angus and colleagues' criteria for detecting community-acquired severe sepsis events, stratified by infection category [1]

\begin{tabular}{|c|c|c|c|c|c|c|}
\hline Diagnostic property & Lung $(n=166)$ & Kidney $(n=59)$ & Abdominal $(n=73)$ & Skin $(n=49)$ & Other $(n=32)$ & Overall $(n=379)$ \\
\hline Sensitivity (\%) & $41.0(28.6$ to 54.3$)$ & $43.5(23.2$ to 65.5$)$ & 36.8 (16.3 to 61.6) & 42.9 (9.9 to 81.6$)$ & 58.3 (27.7 to 84.8$)$ & 42.6 (33.7 to 51.9 ) \\
\hline Specificity (\%) & 83.8 (75.3 to 90.3) & $77.8(60.8$ to 89.9$)$ & 88.9 (77.4 to 95.8) & 90.5 (77.4 to 97.3$)$ & 90.0 (68.3 to 98.8$)$ & 0.7 to 88.7$)$ \\
\hline Positive predictive value (\%) & 59.5 (43.3 to 74.4$)$ & $55.6(30.8$ to 78.5$)$ & 53.8 (25.1 to 80.8 ) & 42.9 (9.9 to 81.6$)$ & 77.8 (40.0 to 97.2$)$ & 58.4 (47.5 to 68.8$)$ \\
\hline Negative predictive value (\%) & $71.0(62.1$ to 78.8$)$ & $68.3(51.9$ to 81.9$)$ & 80.0 (67.7 to 89.2$)$ & 90.5 (77.4 to 97.3$)$ & 78.3 (56.3 to 92.5$)$ & 75.9 (70.5 to 80.7$)$ \\
\hline Likelihood ratio positive & 2.5 (1.5 to 4.3$)$ & 2.0 (0.9 to 4.2$)$ & 3.3 (1.3 to 8.6$)$ & $4.5(1.3$ to 15.9$)$ & $5.8(1.4$ to 23.6$)$ & 3.0 (2.1 to 4.3$)$ \\
\hline Likelihood ratio negative & 0.70 (0.56 to 0.88$)$ & 0.73 (0.49 to 1.08$)$ & 0.71 (0.50 to 1.01$)$ & 0.63 (0.33 to 1.21$)$ & 0.46 (0.23 to 0.92$)$ & 0.67 (0.57 to 0.79$)$ \\
\hline Area under ROC curve & $0.62(0.55$ to 0.70$)$ & 0.61 (0.48 to 0.73$)$ & 0.63 (0.51 to 0.75$)$ & 0.67 (0.46 to 0.87$)$ & 0.74 (0.58 to 0.90$)$ & 0.64 (0.59 to 0.69$)$ \\
\hline
\end{tabular}

Data presented as mean ( $95 \%$ confidence interval). ROC, receiver operating characteristics.

Sweden, Wilhelms and colleagues showed threefold variation in the estimated incidence of severe sepsis using three different definitions for severe sepsis [19]. Similarly, using US national data, Gaieski and colleagues observed twofold variations in hospital severe sepsis mortality with differing severe sepsis definitions [7]. Using data on 1,735 patients from a single academic medical center, Whittaker and colleagues showed that that the Angus-severe sepsis discharge criteria tend to select for a more severely ill severe sepsis cohort, with increased lactates, rates of ICU admission, Acute Physiology and Chronic Health Evaluation II scores and 28-day mortality [5]. Our study affirmed higher rates of hospital mortality among Martin-sepsis and Angus-severe sepsis cases. Curiously, our differing rates of hospital mortality were accompanied by similarities in initial MEDS and SOFA scores, rates of ICU admission, and baseline comorbidity profiles. These observations may indicate that the Martin-sepsis and Angus-severe sepsis criteria select patients that tend to decompensate later in the hospital course.

Our study adds to the body of literature evaluating strategies for identifying sepsis and severe sepsis. Select studies have evaluated the accuracy of the Martin and colleagues' and Angus and colleagues' criteria for sepsis and severe sepsis detection. Using expert review of medical records, Iwashyna and colleagues evaluated the accuracy of Angus and colleagues' criteria for severe sepsis identification, finding similarly low sensitivity (50\%) but slightly higher specificity (96\%) than in our series [9]. However, their series originated from a single center and was limited to a random selection of 111 hospitalizations. Poulose and colleagues conducted a similar analysis evaluating the accuracy of discharge diagnoses for identifying 99 cases of septic shock, but this study was limited to ICU patients [20]. Our contrasting analysis encompassed a larger series of sepsis and severe sepsis events from multiple centers, used structured laboratory and vital signs to define organ dysfunction, and focused upon initial hospital presentation. We additionally evaluated Martin and colleagues' criteria for sepsis, which was not done in the other studies [3].

\section{Limitations}

Because the REGARDS cohort contains individuals older than 45 years old only, we could not characterize sepsis in younger individuals. By design, the REGARDS cohort includes only African Americans and whites, and thus these results may not generalize to other ethnic groups. While the REGARDS trial was designed to study stroke, not sepsis, we were able to take advantage of important features of the study, including the large participant base, extensive baseline information and extended observation period. As is customary for studies of this design, the parent REGARDS study used participant reports of hospitalization events, and thus we may have underestimated the number of serious infection hospitalizations. However, our methodology encompassed detailed manual review of each reported event to verify pertinent clinical information. We note that recall and reporting bias are present in all of the strategies described in this study, including those based on discharge diagnoses.

As discussed previously, our study focused on a subset of 379 hospitalizations with hospital discharge data available at the time of analysis. We did not systematically sample events from the 3,431 serious infection hospitalizations of the larger REGARD-Sepsis study. Also, our analysis examined only hospitalizations attributed to an infection; unidentified sepsis events may have occurred among other hospitalizations. We are in the process of linking serious infection events with Medicare claims data, affording a more robust analysis that may address these concerns.

We applied the Martin-sepsis and Angus-severe sepsis criteria using all available discharge diagnoses. The observed specificities may be even higher if we were able to narrow the analysis to conditions present on hospital admission. However, present-on-admission flags are available only with select hospital discharge datasets [21]. To classify sepsis using hospital data we used information available from the first 28 hours of hospitalization - the observed number of sepsis and severe sepsis events (and potentially the sensitivity of Martin-sepsis and Angus-severe sepsis criteria) would have been higher with the availability of 
Table 6 Baseline participant characteristics and hospital course of community-acquired severe sepsis events (identified by manual chart review) and severe sepsis events identified by Angus and colleagues' discharge diagnoses

\begin{tabular}{|c|c|c|c|c|c|}
\hline Characteristic & $\begin{array}{l}\text { Community-acquired } \\
\text { severe sepsis } \\
\text { (column \%) }(n=122)\end{array}$ & $\begin{array}{l}\text { Angus-severe } \\
\text { sepsis (column \%) } \\
(n=89)\end{array}$ & $\begin{array}{l}\text { Discordances favoring } \\
\text { community-acquired } \\
\text { severe sepsis } \\
\text { (column } \%)(n=70)\end{array}$ & $\begin{array}{l}\text { Discordances favoring } \\
\text { Angus-severe sepsis } \\
\text { (column \%) }(n=37)\end{array}$ & $\begin{array}{l}P \text { value Community- } \\
\text { acquired versus } \\
\text { Angus-severe sepsis } \\
\text { discordances }^{\mathrm{a}}\end{array}$ \\
\hline Age (mean $\pm S D)$ & $70.3(8.9)$ & $72.1(8.6)$ & $69.3(8.9)$ & $72.9(8.4)$ & 0.049 \\
\hline \multicolumn{6}{|l|}{ Sex } \\
\hline Male & 65.9 & 65.2 & 62.9 & 64.9 & \multirow[t]{2}{*}{0.84} \\
\hline Female & 34.1 & 34.8 & 37.1 & 35.1 & \\
\hline \multicolumn{6}{|l|}{ Race } \\
\hline White & 65.6 & 68.5 & 70.0 & 18.9 & \multirow[t]{2}{*}{0.21} \\
\hline B lack & 34.4 & 31.5 & 30.0 & 81.1 & \\
\hline \multicolumn{6}{|l|}{ Income } \\
\hline$<\$ 20,000$ & 23.8 & 29.2 & 20.0 & 29.7 & \multirow[t]{5}{*}{0.43} \\
\hline$\$ 20,000$ to 34,000 & 36.9 & 36.0 & 38.6 & 37.8 & \\
\hline$\$ 35,000$ to 74,000 & 21.3 & 20.2 & 18.6 & 13.5 & \\
\hline$\geq \$ 75,000$ & 10.7 & 5.6 & 14.3 & 5.4 & \\
\hline Unknown & 7.4 & 9.0 & 8.6 & 13.5 & \\
\hline \multicolumn{6}{|l|}{ Education } \\
\hline Less than high school & 23.8 & 22.5 & 22.9 & 18.9 & \multirow[t]{4}{*}{0.91} \\
\hline High school graduate & 27.1 & 28.9 & 31.4 & 37.8 & \\
\hline Some college & 30.3 & 32.6 & 21.4 & 18.9 & \\
\hline College or higher & 18.9 & 16.9 & 24.3 & 24.3 & \\
\hline \multicolumn{6}{|l|}{ Health behaviors } \\
\hline \multicolumn{6}{|l|}{ Tobacco use } \\
\hline Never & 31.4 & 28.4 & 37.1 & 35.1 & \multirow[t]{3}{*}{0.98} \\
\hline Past & 53.7 & 55.7 & 50.0 & 51.4 & \\
\hline Current & 14.9 & 15.9 & 12.9 & 13.5 & \\
\hline \multicolumn{6}{|l|}{ Alcohol use } \\
\hline None & 65.3 & 71.9 & 63.8 & 78.4 & \multirow[t]{3}{*}{0.29} \\
\hline Moderate & 30.6 & 24.7 & 31.9 & 18.9 & \\
\hline Heavy & 4.1 & 3.4 & 4.4 & 2.7 & \\
\hline \multicolumn{6}{|l|}{ Chronic medical conditions } \\
\hline Atrial fibrillation & 16.7 & 18.4 & 17.1 & 21.6 & 0.58 \\
\hline Cancer & 18.1 & 25.8 & 11.3 & 24.0 & 0.16 \\
\hline Chronic kidney disease & 32.0 & 34.8 & 27.1 & 29.7 & 0.78 \\
\hline Chronic lung disease & 12.3 & 13.5 & 12.9 & 16.2 & 0.64 \\
\hline Coronary artery disease & 33.6 & 37.5 & 38.2 & 51.4 & 0.20 \\
\hline Deep vein thrombosis & 14.9 & 13.6 & 13.0 & 8.3 & 0.46 \\
\hline Diabetes & 34.4 & 42.1 & 32.9 & 50.0 & 0.09 \\
\hline Dyslipidemia & 61.8 & 74.7 & 61.8 & 72.7 & 0.28 \\
\hline Hypertension & 68.9 & 75.3 & 68.6 & 83.8 & 0.08 \\
\hline Myocardial infarction & 21.7 & 22.7 & 26.1 & 32.4 & 0.49 \\
\hline Obesity (abnormal BMI or WC) & 63.1 & 67.4 & 58.6 & 62.9 & 0.52 \\
\hline Peripheral artery disease & 4.1 & 7.9 & 1.43 & 8.11 & 0.09 \\
\hline Stroke & 20.7 & 20.2 & 18.8 & 16.2 & 0.74 \\
\hline
\end{tabular}


Table 6 Baseline participant characteristics and hospital course of community-acquired severe sepsis events (identified by manual chart review) and severe sepsis events identified by Angus and colleagues' discharge diagnoses (Continued)

\begin{tabular}{|c|c|c|c|c|c|}
\hline \multicolumn{6}{|l|}{ Infection type } \\
\hline Lung & 50.0 & 47.2 & 51.4 & 46.0 & \multirow[t]{5}{*}{0.88} \\
\hline Kidney & 18.9 & 20.2 & 18.6 & 21.6 & \\
\hline Abdominal & 15.6 & 14.6 & 17.1 & 16.2 & \\
\hline Skin & 5.7 & 7.9 & 5.7 & 10.8 & \\
\hline Other & 9.8 & 10.1 & 7.1 & 5.4 & \\
\hline 28-hour SOFA score & 2 (1 to 3$)$ & $3(2$ to 4$)$ & 2 (1 to 3 ) & 3 (1 to 4$)$ & 0.01 \\
\hline Median (IQR) MEDS score & 10.5 (6 to 13$)$ & $11(8$ to 14$)$ & 9 (6 to 11$)$ & 9 (8 to 14$)$ & 0.25 \\
\hline Admission to ICU & 16.4 & 24.7 & 7.1 & 18.9 & 0.07 \\
\hline Hospital mortality & 11.5 & 22.5 & 4.3 & 24.3 & 0.002 \\
\hline
\end{tabular}

BMI, body mass index; IQR, interquartile range; MEDS, Mortality in Emergency Department Sepsis; SD, standard deviation; SOFA, Sequential Organ Failure Assessment;

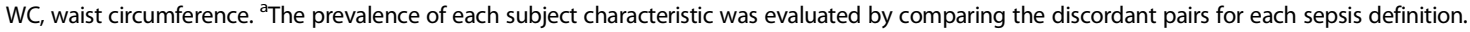

additional hospital data. Also, we coded missing values as zero or absent, which may have altered the number of criterion-standard sepsis and severe sepsis cases.

\section{Conclusion}

Discharge diagnoses show good specificity but poor sensitivity for detecting community-acquired sepsis and severe sepsis events. Discharge diagnoses select for higher mortality sepsis and severe sepsis cohorts. The epidemiology of cohort may vary with differing approaches to sepsis event identification.

\section{Key messages}

- The Martin-sepsis discharge diagnoses are poorly sensitive but highly specific for identifying community-acquired sepsis.

Table 7 Comparison of manual medical record review for identification of criterion-standard community-acquired sepsis and severe sepsis, and of Martin and colleagues' and Angus and colleagues' discharge diagnoses for sepsis identification [1,3]

\begin{tabular}{|c|c|c|}
\hline Characteristic & $\begin{array}{l}\text { Manual medical record review for identification of } \\
\text { community-acquired sepsis and severe sepsis }\end{array}$ & $\begin{array}{l}\text { Martin and colleagues' and Angus and colleagues' discharge } \\
\text { diagnoses for identification of sepsis and severe sepsis }\end{array}$ \\
\hline Data source & $\begin{array}{l}\text { Manual review of initial hospital records (emergency } \\
\text { department and admission notes and laboratory test } \\
\text { results from the first } 28 \text { hours of hospitalization) }\end{array}$ & Hospital discharge diagnosis codes \\
\hline \multirow[t]{2}{*}{$\begin{array}{l}\text { Criteria for sepsis } \\
\text { or severe sepsis }\end{array}$} & Sepsis [infection $+\geq 2$ SIRS criteria] & $\begin{array}{l}\text { Sepsis: ICD-9 discharge diagnoses for sepsis (Martin and } \\
\text { colleagues; Additional file 1) }\end{array}$ \\
\hline & Severe sepsis [sepsis $+\geq 1$ SOFA organ dysfunction] & $\begin{array}{l}\text { Severe sepsis: ICD-9 discharge diagnoses for [infection + organ } \\
\text { dysfunction] (Angus and colleagues; Additional file 2) }\end{array}$ \\
\hline Timeframe/horizon & 28 hours & Entire hospital stay \\
\hline \multirow[t]{4}{*}{ Strengths } & Based upon structured review of medical records & Can utilize existing hospital discharge data \\
\hline & Focused on initial hospitalization (community-acquired sepsis) & \\
\hline & $\begin{array}{l}\text { Verified connection between infection and sepsis } \\
\text { (infection must be major reason for hospitalization) }\end{array}$ & \\
\hline & Extensive data on pre-existing comorbid conditions & \\
\hline \multirow[t]{4}{*}{ Limitations } & Limited to the REGARDS cohort & Limited information on pre-existing comorbid conditions \\
\hline & Requires manual review of medical records & $\begin{array}{l}\text { Cannot differentiate initial (community-acquired) from } \\
\text { later (hospital-acquired) sepsis }\end{array}$ \\
\hline & \multirow{2}{*}{$\begin{array}{l}\text { Limited to initial hospitalization presentation and } \\
\text { records - cannot detect later (hospital-acquired) sepsis }\end{array}$} & Depends upon accuracy of coded discharge diagnoses \\
\hline & & $\begin{array}{l}\text { Assumes connection between coded infection and organ } \\
\text { dysfunction (Angus and colleagues) }\end{array}$ \\
\hline
\end{tabular}


- The Angus-severe sepsis discharge diagnoses are poorly sensitive but highly specific for identifying community-acquired severe sepsis.

- The Martin-sepsis and Angus-severe sepsis criteria select for subgroups with higher mortality than those selected by medical record review. Other subject characteristics are similar.

- Epidemiologic studies of sepsis must consider the strengths and limitations of different sepsis detection strategies.

\section{Additional files}

Additional file 1: Is a table presenting the ICD-9 discharge diagnoses for sepsis, adopted from Martin and colleagues [3].

Additional file 2: Is a table presenting the ICD-9 infection and organ dysfunction discharge diagnoses, adopted from Angus and colleagues [1]. Severe sepsis defined by the presence of both infection and organ dysfunction.

\section{Abbreviations}

ICD-9: International Classifications of Diseases, 9th edition; MEDS: Mortality in Emergency Department Sepsis; REGARDS: Reasons for Geographic and Racial Differences in Stroke; SOFA: Sequential Organ Failure Assessment.

\section{Competing interests}

MMS reports the following potential conflicts of interest: Amgen, salary support to study patterns of statin use in Medicare and other large databases; diaDexus, salary support for a research grant on lipids and coronary heart disease outcomes; diaDexus, consulting to help with US Food and Drug Administration application; and $\mathrm{NIH}$ and $\mathrm{AHRQ}$, salary support for research grants. JWB reports consulting for Merck, Pfizer and Astellas, and receipt of a research grant from Bristol-Myers Squibb. The remaining authors declare that they have no competing interests.

\section{Authors' contributions}

HEW, DRA, NIS and JWB conceived the study. HEW and MMS organized and oversaw data collection. HEW, DRA, JPD and RLG conducted the analysis, and all authors contributed to review of the results. HEW drafted the manuscript, and all authors contributed to its editorial review and revision. HEW assumes responsibility for the work as a whole. All authors read and approved the manuscript.

\section{Acknowledgements}

This study was supported by award R01-NR012726 from the National Institute for Nursing Research, UL1-RR025777 from the National Center for Research Resources, as well as by grants from the Center for Clinical and Translational Science and the Lister Hill Center for Health Policy of the University of Alabama at Birmingham. The parent REGARDS study was supported by cooperative agreement U01-NS041588 from the National Institute of Neurological Disorders and Stroke, National Institutes of Health, Department of Health and Human Service. The content is solely the responsibility of the authors and does not necessarily represent the official views of the funding agencies. Representatives of the funding agencies have been involved in the review of the manuscript but not directly involved in the collection, management, analysis or interpretation of the data. The authors thank the other investigators, the staff, and the participants of the REGARDS study for their valuable contributions. A full list of participating REGARDS investigators and institutions can be found online (http://www. regardsstudy.org and http://www.regardssepsis.org). The authors particularly thank Jessica R Bradford and Binh C Vu for their assistance with data collection.

\section{Author details}

'Department of Emergency Medicine, University of Alabama School of Medicine, 619 19th Street South, OHB 251, Birmingham, AL 35249, USA.
${ }^{2}$ University of Alabama School of Medicine, Birmingham, Alabama, USA. ${ }^{3}$ Department of Epidemiology, School of Public Health, University of Alabama at Birmingham, Birmingham, Alabama, USA. ${ }^{4}$ Department of Medicine, Division of Preventive Medicine, University of Alabama School of Medicine, Birmingham, Alabama, USA. ${ }^{5}$ Department of Emergency Medicine, Beth Israel Deaconess Medical Center, Boston, Massachusetts, USA. ${ }^{6}$ Department of Medicine, Division of Infectious Diseases, University of Alabama School of Medicine, Birmingham, Alabama, USA.

Received: 31 October 2014 Accepted: 23 January 2015

Published online: 16 February 2015

\section{References}

1. Angus DC, Linde-Zwirble WT, Lidicker J, Clermont G, Carcillo J, Pinsky MR. Epidemiology of severe sepsis in the United States: analysis of incidence, outcome, and associated costs of care. Crit Care Med. 2001;29:1303-10.

2. Wang HE, Shapiro NI, Angus DC, Yealy DM. National estimates of severe sepsis in United States emergency departments. Crit Care Med. 2007;35:1928-36

3. Martin GS, Mannino DM, Eaton S, Moss M. The epidemiology of sepsis in the United States from 1979 through 2000. N Engl J Med. 2003;348:1546-54.

4. Weycker D, Akhras KS, Edelsberg J, Angus DC, Oster G. Long-term mortality and medical care charges in patients with severe sepsis. Crit Care Med. 2003;31:2316-23.

5. Whittaker SA, Mikkelsen ME, Gaieski DF, Koshy S, Kean C, Fuchs BD. Severe sepsis cohorts derived from claims-based strategies appear to be biased toward a more severely ill patient population. Crit Care Med. 2013;41:945-53.

6. Dombrovskiy WY, Martin AA, Sunderram J, Paz HL. Rapid increase in hospitalization and mortality rates for severe sepsis in the United States: a trend analysis from 1993 to 2003. Crit Care Med. 2007;35:1244-50.

7. Shi SF, Zhou FD, Zou WZ, Wang HY. Acute kidney injury and bilateral symmetrical enlargement of the kidneys as first presentation of B-cell lymphoblastic lymphoma. Am J Kidney Dis. 2012;60:1044-8.

8. Flaatten H. Epidemiology of sepsis in Norway in 1999. Crit Care. 2004;8:R180-4.

9. Iwashyna TJ, Odden A, Rohde J, Bonham C, Kuhn L, Malani P, et al. Identifying patients with severe sepsis using administrative claims: patient-level validation of the Angus implementation of the international consensus conference definition of severe sepsis. Med Care. 2014;52:e39-43.

10. Dellinger RP, Levy MM, Rhodes A, Annane D, Gerlach H, Opal SM, et al. Surviving sepsis campaign: international guidelines for management of severe sepsis and septic shock: 2012. Crit Care Med. 2013;41:580-637.

11. Howard VJ, Cushman M, Pulley L, Gomez CR, Go RC, Prineas RJ, et al The reasons for geographic and racial differences in stroke study: objectives and design. Neuroepidemiology. 2005;25:135-43.

12. Vincent JL, Moreno R, Takala J, Willatts S, De Mendonca A, Bruining H, et al. The SOFA (Sepsis-related Organ Failure Assessment) score to describe organ dysfunction/failure: on behalf of the working group on sepsis-related problems of the European Society Of Intensive Care Medicine. Intensive Care Med. 1996;22:707-10.

13. National Institute on Alcohol Abuse and Alcoholism. Helping Patients Who Drink Too Much, a Clinician's Guide. http://pubs.niaaa.nih.gov/publications/ Practitioner/CliniciansGuide2005/guide.pdf 2005. Accessed February 20, 2015

14. Levey AS, Stevens LA, Schmid CH, Zhang YL, Castro 3rd AF, Feldman HI, et al. A new equation to estimate glomerular filtration rate. Ann Intern Med. 2009;150:604-12.

15. Janssen I, Katzmarzyk PT, Ross R. Body mass index, waist circumference, and health risk: evidence in support of current National Institutes of Health guidelines. Arch Intern Med. 2002;162:2074-9.

16. Shapiro NI, Howell MD, Talmor D, Donnino M, Ngo L, Bates DW. Mortality in Emergency Department Sepsis (MEDS) score predicts 1-year mortality. Crit Care Med. 2007:35:192-8.

17. Shapiro NI, Wolfe RE, Moore RB, Smith E, Burdick E, Bates DW. Mortality in Emergency Department Sepsis (MEDS) score: a prospectively derived and validated clinical prediction rule. Crit Care Med. 2003;31:670-5.

18. Muntner P, Gutierrez O, Zhao H, Fox CS, Wright NC, Curtis JR, et al. Validation study of medicare claims to identify older us adults with CKD using the REasons for Geographic and Racial Differences in Stroke (REGARDS) study. Am J Kidney Dis. 2015;65:249-58. 
19. Wilhelms SB, Huss FR, Granath G, Sjoberg F. Assessment of incidence of severe sepsis in Sweden using different ways of abstracting International Classification of Diseases codes: difficulties with methods and interpretation of results. Crit Care Med. 2010;38:1442-9.

20. Poulose JT, Cartin-Ceba R, Shoja A, Paul A, Trillo-Alvarez C, Kashyap R, et al. Comparison of International Classification of Disease - Ninth Revision (ICD-9) coding with retrospective case review for the diagnosis of septic shock. In: C56 sepsis: from bench to the bedside. Am J Resp Crit Care Med 2009;179:A4691 (abstract).

21. Wang HE, Donnelly JP, Shapiro NI, Hohmann SF, Levitan EB. Hospital variations in severe sepsis mortality. Am J Med Qual. Forthcoming 2014. doi:10.1177/1062860614534461

\section{Submit your next manuscript to BioMed Central} and take full advantage of:

- Convenient online submission

- Thorough peer review

- No space constraints or color figure charges

- Immediate publication on acceptance

- Inclusion in PubMed, CAS, Scopus and Google Scholar

- Research which is freely available for redistribution 